\title{
Atualidade da performance das narrativas como vivências continuadas ${ }^{1}$
}

\section{Luciano Vinhosa ${ }^{2}$}

Resumo: Neste ensaio avançaremos a ideia de que a performance, a partir de seus agregados residuais, tais como a fotografia, os textos críticos, os relatos descritivos e os depoimentos de testemunhas, tem vida continuada nas narrativas que a reconstituem e a recriam no interior de uma comunidade dada. O poder imaginal do sujeito é ferramenta, a mais eficaz, a propiciar essa vida da performance no espaço social.

Palavras-chave: Performance. Imagens. Narrativas.

\section{The Life of Performance Art Narratives as Continuous Experiences}

\begin{abstract}
In this essay, we will advance that performance, based on its residual aggregates, such as photography, critical texts, descriptive reports and testimonies from witnesses, remains updated in the narratives that reconstruct and recreate it. The individual's imaginal power is the tool that provides this life of performance in the social space.
\end{abstract}

Keywords: Performance. Images. Narratives.

1 Esta pesquisa é desenvolvida com apoio do CNPq (Bolsa de Produtividade em Pesquisa), órgão do governo brasileiro de fomento à pesquisa, a quem devo meus agradecimentos.

2 Artista e teórico da arte. Arquiteto e Urbanista graduado pela UFF; Mestre em Artes Visuais pela EBA-UFRJ; Doutor em Estudos e Práticas Artísticas pela Universidade do Québec em Montréal, Canadá. Vínculo institucional: Universidade Federal Fluminense, Rua Lara Vilela 126, São Domingos - Niterói, RJ, 24210-590. E-mail: lucianovinhosa@id.uff.br. ORCID: https://orcid.org/0000-0001-8593-1223. Lattes iD: http://lattes.cnpq.br/9844925998185463. Niterói, Brasil. Bolsista de produtividade, o autor agradece ao CNPq, órgão do governo brasileiro de fomento à pesquisa, por financiar esta pesquisa. 


\section{Introduzindo a questão}

Que a maioria das performances realizadas nos anos 1960 e 1970 tenha chegado aos dias de hoje mediante seus registros, e que esses têm alimentado grande parte das investigações da história da arte, não é novidade para ninguém. As especulações atuais, porém, acerca de que tais registros não seriam somente fontes documentais, mas atualizações continuadas dessas experiências por meio da imagem, acrescentam um novo viés ao assunto. Essa tomada de consciência se deve sobretudo às recentes teorias da imagem, que passaram a entender a fotografia não somente a partir de sua matriz indicial, mas conjugando-a com a de seu devir icônico, a representação. Em outras palavras, o estatuto de imagem que acarreta a fotografia não a quer tão somente como vestígio do que aconteceu, mas a entende como campo intencional de construção no ato do enquadramento e corte. Nesse sentido, a fotografia, além de objeto de nossa percepção visual, o é também de expressão, por um lado, e, por outro, de interpretação conceitual e simbólica. Se o tom expressivo responde à construção no ato do registro, ao público cabe o entendimento e atribuição de sentidos à imagem.

Dessa forma, como as duas faces de uma mesma moeda, a recepção icônica da fotografia não está, de modo algum, dissociada da dobra indicial que presta testemunho da ação que aconteceu: o "isto foi" (BARTHES, 2003). Essa característica, que de certa forma a distancia do espaço ideal que o ícone criou para si a fim de religar-se unicamente ao referente a partir de uma representação convencional - como no caso da pintura -, é, no entanto, aquilo que faz a fotografia ancorar-se no mundo, religar-se aos fatos, aos afetos vividos e aos acontecimentos pretéritos. Essa qualidade paradoxal a torna fonte incansável de produção de novas imagens mentais e especulativas porque, como enquadramento e corte, ela remete a uma continuidade extracampo em que, supomos, aconteceu o evento em sua totalidade, embora só o possamos imaginar. Eis aqui o vórtice central de uma experiência promovida pelo documento, quando a representação econômica que ele nos dá da performance - uma imagem infra-mince, um quase nada que a fotografia [não]mostra - se remete ao acontecimento, que de suposto se desdobrou no tempo e em espaço determinado, e que de certo modo estimula as faculdades especulativas da imaginação mais do que nos revela os fatos.

Assim, na sequência, iremos nos ater às fotografias produzidas intencionalmente como documentos, sobretudo às de performance porque se pretendem registros neutros. Evidentemente, existem outros tipos de imagem 
fotográfica, mesmo considerando o universo do analógico e de sua prática eventualmente continuada no uso de aparelhos digitais, que não se acomodam tão facilmente na categoria documental porque alçam sobremaneira o caráter de imagem ao privilegiar o aspecto icônico em detrimento daquele indicial. ${ }^{3}$ Neste ponto temos um divisor de águas bastante interessante: sendo sempre um documento, a prática de alguns artistas cedo entendeu e soube discernir os registros de performance das performances encenadas para a câmera. Dito de outra forma: as ações ao vivo que, eventualmente, foram registradas, das performances em imagens. Ambos os casos, intencionalmente ou não, tiram proveito do potencial inesgotável da competência imaginal do sujeito (BELTING, 2014).

Inicialmente nos deteremos na exposição das diferenças entre esses dois tipos de imagens mencionados para chegar em seguida precisamente aonde queremos: pensar a performance não somente como um evento pontual localizado em um passado ao qual não temos mais acesso, mas antes como um agregado narrativo que o atravessa, o refaz e o atualiza no presente a partir de vestígios e testemunhos deixados - textos, restos materiais, vestígios de ações, relatos, críticas -, sendo a fotografia uma das componentes necessárias à vida continuada da performance.

\section{Documento de performance e a performance como documento}

No caso do documento como performance, podemos recorrer à posição de Allan Kaprow que toma a ação performativa ou, mais precisamente, o happening - porque ainda não se tratava, nos anos 1950, de performance - como evento pontual que se esgota no tempo de sua apresentação ou de reapresentação, quando reencenado a partir de instruções legadas pelo artista, mas que se torna um novo acontecimento a cada nova atuação. Kaprow, quando publica sua ontologia, um livro repleto de imagens documentais de seus happenings, sustenta em breve texto que a autonomia daquelas imagens em relação às ações é fato notório, uma vez que o que se passou não poderá ser jamais acessado por meio de seus registros, sempre parciais, ainda que acompanhados de relatos (DELPEUX, 2010).

3 Emprego o termo "imagem" quando o caráter icônico e/ou representacional da fotografia prevalece sobre ao caráter indicial do registro. André Rouillé (2009) refere-se à categoria expressão, por exemplo, ao abordar os diferentes tipos de produção fotográfica que não se enquadram simplesmente em documentos. Também podemos nos remeter a certa prática fotográfica, destacada por Jean Fontcuberta (2012), que induz, por meio da construção da imagem, ficções deliberadas. 
Em outras palavras, não existe mediação possível. O que foi feito está para sempre perdido no passado por se tratar de iniciativas que se desdobraram em situação espaçotemporal específica. Ao tomar essa posição, o artista separa ontológica e acertadamente os dois modos de experiência: o da ação efetiva, que afirma o aqui e agora do acontecimento, e o da imagem, que não seria mais que lembrança destinada a "impressionar a imaginação do espectador", e não algo para reconstituir os fatos (DELPEUX: 2010, p. 10). Trata-se, portanto, de objetos bastante distintos, com lugares jamais mutuamente intercambiáveis, mas de algum modo intercomunicáveis por qualquer tipo de reminiscência que age no sujeito estimulando-o a criar novas imagens especulativas, posto que as fotografias "impressionam a sua imaginação".

Em outro extremo e a título de exemplo, podemos citar a fotoperformance Tentativa de sair do quadro (Fig. 1), que Orlan encenou para a objetiva em 1965. Na imagem vê-se o corpo contorcido da artista ao simular uma fuga do enquadramento tradicional da pintura, a moldura. Evidentemente, ao se utilizar do registro de uma ação, trata-se, no caso, mais de agir sobre um certo contexto de produção discursiva do que de sugerir um intervalo narrativo, propriamente ficcional. Seria correto afirmar que, nessa imagem, a artista elabora a representação de um conceito - talvez o de corpo feminino, há tanto tempo apropriado e objetificado pela arte e, no mesmo enlace, o de uma possível arte agora habitando o corpo de cada um - que somente a fotografia poderia reificar ao congelar o gesto performático preciso, de outro modo efêmero, sem densidade poética e sem expressão conceitual. Na época em que fez o trabalho, a discussão acerca do esgotamento da pintura e da representação que o quadro de cavalete encerra estava na ordem do dia. Por outro lado, a necessidade de o artista lançar-se diretamente no mundo, a aclamação da vida como arte, culminaria, em alguns casos, com a singularização da performance como modalidade artística, diferente da pintura e da escultura. Dizemos em alguns casos porque a partir dessa mesma problemática, os caminhos se bifurcaram por diferentes respostas e, nessa empreitada, nem sempre a performance foi a única via a se seguir, cabendo, portanto, relativizá-la. ${ }^{4} \mathrm{O}$ certo é que esse problema, já levantado por Kaprow nos finais dos anos 1950, alimentou o debate estético na década de 1960 e motivou a prática experimental

4 Considerando apenas o quadro das práticas artísticas no Brasil, artistas como Hélio Oiticica e Lygia Pape, por exemplo, motivados pelo mesmo problema, levaram sua obra por caminhos muito diferentes desse da performance. 
de muitos outros artistas, seus contemporâneos. ${ }^{5}$ As experimentações foram, igualmente, respaldadas por intensa produção teórica, também por parte dos artistas, sobre o esgotamento das formas tradicionais da arte, dos limites da pintura, por exemplo. Por outro lado, experimentaram-se outras formas expressivas de ativação no espaço comum de vida por convocação à participação do espectador, e a performance foi uma delas. Essa história já a conhecemos muito bem, mas é necessário relembrá-la porque é justamente diante desse quadro prático/teórico que o gesto de Orlan se reveste de sentido, desdobra-se contextualmente e se torna a expressão conceitual da vida como arte. Diante da imagem, cuja moldura barroca coincide com as laterais do enquadramento fotográfico ao mesmo tempo que separa os eventos no interior do quadro e os do mundo fora dele, ela não nos sugere exatamente um extracampo em virtude do corte justo que promove, mas pela forma como o corpo contorcido da artista se faz emergir de um passado e avançar em nosso espaço. O que vemos é uma mulher ainda muito jovem e nua, uma virgem que se esforça para sair de um fundo mítico e escuro da história da arte. A Vênus, já renascida, tenta projetar-se em nosso mundo contemporâneo. Com esse gesto simbólico, Orlan encarna a própria alegoria da arte em sua evidência sensual, referência ao modo sensível como a pintura assedia o espectador. Seu braço, apoiado na moldura, é a alavanca que a impulsiona para fora, sua cabeça, em primeiro plano, invade nosso espaço em alusão ao nascimento. Mas, não nos encara de frente. Reclinada, vira-se para o lado esquerdo. O olhar, direcionado para cima, guarda curiosidade e encantamento comedidos em relação ao novo mundo que se abre. Se o campo inscrito no quadro da imagem aponta para uma história, de fato para uma tradição da pintura muito antiga, o extracampo nos força a olhar para o mundo ao nosso redor.

Essa performance, pensada pela fotografia, se realiza como imagem-conceito que se representa a si mesma e se apresenta ao olhar do outro como fato inédito. Como imagem que frequenta os corpos, dependerá tão somente de um sujeito (de um corpo) para animá-la com suas próprias histórias. Se, como exposto acima, nela pudemos ver com clareza a história

5 Kaprow (1958, apud Ferreira, Cotrim, 2006), em O legado de Pollock, já colocava esse problema muito claramente. Por outro lado, Ferreira Gullar (1958, apud Clark, 1980) no ensaio Lygia Clark: uma experiência radical, aborda o problema por outro viés, salientando o modo como as pesquisas de Lygia caminharam para a anulação do espaço pictórico - primeiro com a absorção da moldura que o separava do mundo, depois com suas superfícies moduladas que ativam o plano pictórico em espaço e tempo reais. 
da arte, outros sujeitos, com suas distintas sensibilidades, poderão trazer à tona outros enredos. A performance como imagem - a fotografia que plasma a ideia no gesto congelado - compartilha do mesmo efeito de presença que outros objetos tradicionais da história da arte, como a pintura e a escultura, assumem diante de nossos olhos e a cada vez que eles nos olham. Nesse sentido, funcionariam exatamente ao contrário dos happenings que, se adotamos a posição de Kaprow, esgotam-se enquanto ação temporal no contexto específico de sua realização. Isso, entretanto, somente a princípio, porque, mesmo os documentos, por mais descritivos que sejam, e Kaprow sabe disso muito bem, podem, em alguma medida,

Figura 1

Orlan

Tentative de sortir $\mathrm{du}$ cadre, 1965 fotografia em preto e branco (dimensões não mencionadas)

Fonte:

Orlan, 2004, p.4

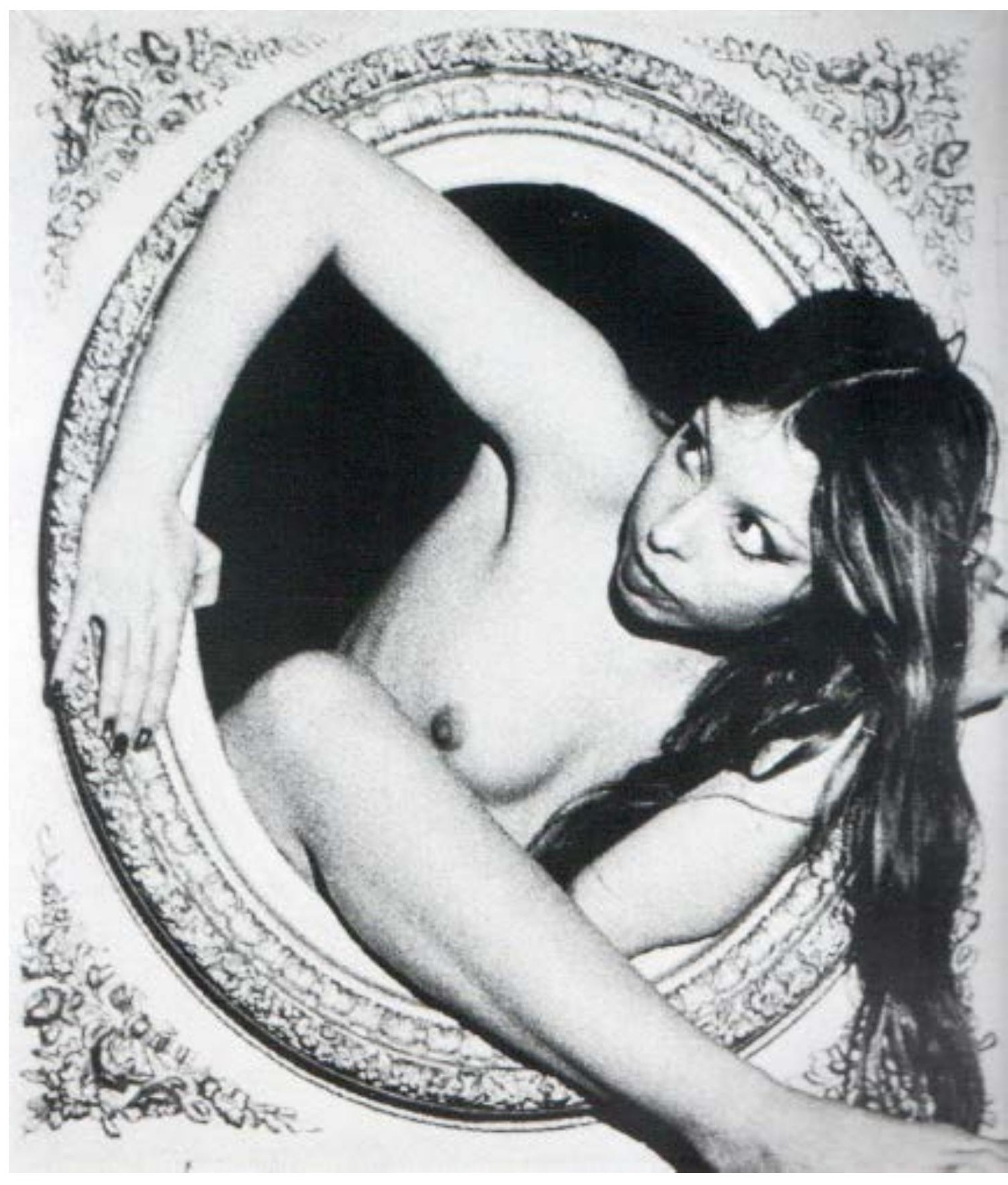


funcionar como imagens.

\section{A performance e seus agregados ou do documento como performance}

E se, entre o documento duro, com a sua capacidade de impressionar nossa imaginação, e a ação pensada pela fotografia, pudéssemos tomar a performance em si mesma - não como evento efêmero e pontual, mas um agregado vivo de vestígios que corroborasse para a gênese de narrativas sempre refeitas por seus interlocutores e cocriadores -, nós, os espectadores das imagens documentais? Essa hipótese me pareceu plausível na ocasião da apresentação, no encontro anual da Anpap (Associação Nacional de Pesquisadores em Artes Plásticas), da comunicação de Aline Dias, "This is new: situações construídas", a propósito de uma performance de Tino Sehgal integrando a coleção do Museu de Arte Contemporânea de Seralves, cidade do Porto, Portugal. ${ }^{6}$ Como é fato corrente, as performances de Sehgal não admitem qualquer tipo de documentação que as testemunhe, seja por escrito, seja por imagens ou por quaisquer outros meios senão o relato oral, garantindo sua comercialização e único insumo para sua reapresentação.

Tino Sehgal, à parte sua deliberada poética, que se sustenta na fina dialética envolvendo a criação de objetos imateriais, e sua quase inacreditável absorção pelo mercado de arte, parece antes apostar na performance como uma espécie de narrativa viva e sempre atual. Nesse caso, podemos tomá-la como entidade disponível no espaço comum, inconclusa e por isso mesmo dinâmica e aberta à experiência coletiva de uma comunidade ou grupo social dado, ${ }^{7}$ tudo de acordo com o modo como Walter Benjamin (1994) entendeu e definiu esse fenômeno ligado à experiência humana:

A informação só tem valor no momento em que é nova. Ela só vive nesse momento,

6 Essa comunicação foi apresentada no 27o Encontro Nacional de Pesquisadores em Artes Plásticas (Anpap), 2018, no âmbito do Simpósio "A produção da imagem como vetor da experiência", coordenado por mim, Beatriz Raucher e Tatiana Ferraz. Disponível em: <http://anpap.org.br/ anais/2018/>. Acesso em:12/09/2020.

7 O termo "comunidade" me perece mais preciso, uma vez que a arte, seus objetos e problemas atingiriam mais de imediato os membros de um grupo social específico: aqueles sujeitos circunscritos no interior de sua prática e dinâmica ou, de forma mais ampla, aqueles para quem a arte importa ou que por ela se deixam, espontaneamente, afetar. Nesse caso, estou atribuindo ao termo o mesmo teor que Wittgenstein (1996) Ihe confere em suas Investigações filosóficas quando, ao analisar os jogos de linguagem, afirma que seu sentido reside unicamente em uma "forma de vida ou comunidade". 
precisa entregar-se inteiramente a ele e sem perda de tempo tem que se explicar nele. Muito diferente é a narrativa. Ela não se entrega. Ela conserva suas forças e depois de muito tempo ainda é capaz de se desenvolver. [...]

Nada facilita mais a memorização das narrativas que aquela sóbria concisão que as salva da análise psicológica. Quanto maior a naturalidade com que o narrador renuncia às sutilezas psicológicas, mais facilmente a história se gravará na memória do ouvinte, mais completamente ela se assimilará à sua própria experiência e mais irresistivelmente ele cederá à inclinação de recontá-la um dia (BENJAMIN, 1994, p. 204).

Da sofisticação radical de Sehgal, que não permite qualquer tipo de documentação de suas ações, aos meros registros de Kaprow, agora parece-nos viável que mesmo o documento de performance, em sua discreta instância de imagem, possa continuar agindo no imaginário comum da mesma forma que os vestígios materiais, os textos críticos e os relatos de quem a testemunhou continuariam a agir por meio de um "recontar" que bascula o passado, a reconstitui no presente e projeta a performance para um futuro.

Certamente, por sua natureza compartilhada, as narrativas não são somente constitutivas do que entendemos por espaço comum, mas também estão sujeitas à permanente reconstrução subjetiva quando postas em circulação no interior desse mesmo espaço. A faculdade imaginal do sujeito, da qual nos fala Belting (2014), ao se apropriar de um evento seja ele apenas acessado por seus fragmentos residuais disponíveis ao público, tais como os documentos fotográficos e os relatos, por exemplo - e, em contrapartida, fazê-lo retornar ao espaço comunitário, o faz pelo viés das inflexões pessoais que, no entanto, estão frequentemente integradas às experiências do grupo. Essa passagem entre dados exteriores e a sua re-elaboração interior - objeto e sujeito - está de tal forma integrada no ato de contar e recontar, que as instâncias interior/exterior participam de uma só forma de vida partilhada, a qual poderíamos chamar de sujeito social ou de comunidade. A respeito, o autor esclarece:

As nossas imagens interiores nem sempre são de natureza individual, mas, mesmo se forem de origem coletiva, são de tal modo interiorizadas por nós, que as temos por genuínas imagens (BELTING, 2014, p. 33).

Nesse caso, os registros de performances não atestariam simplesmente os fatos, mas os produziriam de forma reelaborada, sempre, porém, os remetendo aos acontecimentos passados, porque induzem a um esforço de narrativa construído sobre a ilusão descritiva dos documentos, supostamente desvinculado das vivências e das interpretações pessoais, como 
se os fatos pretéritos pertencessem unicamente ao espaço social; tudo de acordo com o que nos sugere Benjamin na passagem antes citada, quando afirma que o narrador deve renunciar "às sutilezas psicológicas".

A conexão direta que o documento estabelece com o real é o modo operacional da discreta ilusão produtiva do índice. Essa ilusão alimenta nossa imaginação de forma tão sutil, como se o meio fosse transparente, e o registro pudesse nos conduzir diretamente aos fatos enquanto permanecemos divagando, sem nos dar conta, sobre a superfície da imagem. Com efeito, as fotografias de performance são capazes de impressionar a nossa imaginação, como sustenta Kaprow, além de, em retorno, incitar nossa faculdade imaginal, nossa capacidade de criar imagens. É por meio dessa competência inata que a imagem é agente incansável de produção de novas imagens que alimentam, em retorno, o repertório narrativo circulando no espaço social.

Em se tratando de performance, essas imagens, ao contrário do que comumente supomos, no lugar de prestarem-se a reconstituir um passado, são capazes de instaurar novos acontecimentos performativos, sempre atuais, que irão integrar a performance no imaginário coletivo em circulação no interior de uma comunidade dada. Nesse sentido, podemos afirmar que a performance se revigora sem cessar no sujeito social de sua narrativa, entidade meio-termo, supostamente situada entre os dois extremos de subjetividades: a daquele que conta - o narrador - e a de quem a escuta e a faz avançar. A vida persistente da performance está na mesma medida em que suas imagens são capazes de continuar a agir em nós e, simultaneamente, no mundo do qual participamos.

Philip Auslander (2019) desenvolve no ensaio A performatividade na documentação de performance a argumentação de que os documentos de performance guardam em si performatividade. $\mathrm{O}$ autor entende pelo termo um certo modo de agir continuado da imagem. Para elaborar seu conceito, tudo como em nossos dois exemplos iniciais de Kaprow e de Orlan, ele confronta dois tipos de imagens, a documental com outra que ele chama de teatral. Esta última, como no caso de Orlan, é uma performance pensada como imagem elaborada através do dispositivo fotográfico, levando em conta suas possibilidades e limitações intrínsecas.

Ao expor sua tese, Auslander recorre à filosofia da linguagem desenvolvida por John Langshaw Austin. Em observação aos usos triviais da linguagem, o filósofo britânico diferencia os "atos de fala" dos enunciados que ele chama de constatativos. Atos de fala seriam enunciados performativos porque 
engendram ações como, por exemplo, dizer "declaro fulano e beltrana, marido e mulher" em uma cerimônia de casamento. Não se trata de descrever uma ação, mas de realizá-la. Em contrapartida, enunciados constatativos relatam acontecimentos, "fulano e beltrano se casaram". As fotografias de performance, se a princípio nos parecem descrever acontecimentos passados, funcionariam na realidade, segundo a sugestão de Auslander, como atos de fala, porque, ao mostrar uma ação, elas a (re)produzem: "o ato de documentar um evento como performance é o que a constitui como tal. A documentação não gera simplesmente uma imagem/declaração, a qual descreveria ao mesmo tempo em que afirmaria que performance ocorreu. Ao contrário, ela produz um evento como performance" (p.343). Ela é em si performativa porque nos toma a reboque da ação apresentada quando reelaboramos a performance por meio de sua imagem. Para o autor e por fim, as imagens documentais e teatrais se igualam no que são capazes de engendrar a performance no lugar de descrevê-la.

\section{Concluindo}

Além do caso patente das fotografias, podemos acrescentar outros agregados que se prestariam, no caso da performance, como insumos para a sua vida continuada: textos críticos, prescrições de artistas, relatos de testemunhas. Fica evidente que todos esses excessos que a performance produz a realimentam e a trazem viva em nossos corpos e mentes. Por outro lado, as narrativas que daí derivam, fazem-na avançar em novas frentes renovadas de acontecimentos sociais. É importante frisar este último aspecto, porque a vida da performance só poderia residir no espaço social, comum entre os homens. Daí advém a ideia de que as narrativas se apoiem em registros, ainda que se faça na ilusão constitutiva do índice fotográfico, e não nas idiossincrasias das imagens espontâneas e unicamente subjetivas. Esse modo de compreender a performance, que a toma por sua instância viva e disponível no tecido social, pode acrescentar muito bem uma dobra inédita à discussão e mudar a perspectiva pela qual até então essa modalidade artística vinha sendo tratada.

Se as performances tiveram lugar em um passado, reside em seus restos legados, no entanto, um princípio dialético que as faz funcionar como alavanca propulsora de narrativas que impulsionam o passado para um futuro do presente dos acontecimentos. Assim, a dinâmica envolvendo criação, ação, reprodução e transformação integra a lógica, em si produtiva, da performance. Antes de ser acontecimento vagamente rememorável, definitivamente inscrito em seu contexto original e encerrado no tempo, parece-nos agora muito claramente que a performance é atividade imaginal 
viva, que mantém seu eterno presentificar-se no espaço social, sempre reativada pelos excessos que Ihe foram, definitivamente, agregados.

\section{Bibliografia}

AUSLANDER, Philip. A performatividade na documentação de performances. Poiésis, Niterói, v. 20, n. 33, jan./jun. 2019. pp. 337-352. Disponível em <http://periodicos.uff.br/poiesis/article/view/29014>. Acesso em 05/03/2020.

BARTHES, Roland. La chambe claire: note sur la photographie. Paris: Gallimard, 2003.

BELTING, Hans. Antropologia da imagem. Lisboa: Kkym + EAUM, 2014.

BENJAMIN, Walter. Obras escolhidas: magia e técnica, arte e política. São Paulo: Brasiliense, 1994.

CLARK, Lygia. Lygia Clark. Rio de Janeiro: Funarte, 1980. [Col. Arte Contemporânea Brasileira]

DELPEUX, Sophie. Le corps-caméra: le performer e son image. Paris: Textuel, 2010.

FERREIRA Glória; COTRIM Cecilia. Escritos de artistas: anos 60-70. Rio de Janeiro: Zahar, 2006.

FONTCUBERTA, Joan. A câmara de Pandora: fotografia depois da fotografia. São Paulo: Gustavo Gill, 2012.

ORLAN. Orlan. Paris: Flamarion, 2004.

ROUILLÉ, André. A fotografia: entre documento e arte contemporânea. São Paulo: Senac, 2009.

WITTGENSTEIN, L. J. Johann. Wittgenstein. São Paulo: Nova Cultural. (Col. Os Pensadores).

Recebido em 15 de setembro de 2020 e aceito em 01 de março de 2021.

Este é um artigo publicado em acesso aberto sob uma licença Creative Commons (cc) B Br 